\title{
The Effects of Maternal Rearing Attitudes and Depression on Compulsive-Like Behavior in Children: The Mediating Role of Children's Emotional Traits
}

\author{
Hoshiko Yamauchi1 ${ }^{*}$, Masayoshi Ogura², Yuko Mori' ${ }^{3}$, Hiroyuki Ito ${ }^{4}$, Shuji Honjo 5 \\ ${ }^{1}$ Center for Student Counseling, Nagoya University, Nagoya, Japan \\ ${ }^{2}$ Graduate School of Education, Naruto University of Education, Naruto, Japan \\ ${ }^{3}$ Formerly at the Center for Developmental Clinical Psychology and Psychiatry, Nagoya University, Nagoya, \\ Japan \\ ${ }^{4}$ Research Center for Child Mental Development, Hamamatsu University School of Medicine, Hamamatsu, \\ Japan \\ ${ }^{5}$ Sasagawado-ri General Clinic, Yokkaichi, Japan \\ Email: "hoshiko@nagoya-u.jp
}

Received 9 December 2015; accepted 1 February 2016; published 4 February 2016

Copyright (C) 2016 by authors and Scientific Research Publishing Inc.

This work is licensed under the Creative Commons Attribution International License (CC BY).

http://creativecommons.org/licenses/by/4.0/

(c) (i) Open Access

\section{Abstract}

This study was designed to examine the effects of maternal rearing attitudes and depression on children's compulsive-like behavior, mediated by children's emotional traits. A questionnaire was completed by 116 mothers of 3 - 6-year-old children. There were no significant correlations between maternal factors and compulsive-like behavior in children. However, structural equation modeling using children's emotional traits as the mediating variable indicated that maternal rearing attitudes influence children's compulsive-like behavior via children's anger trait. This finding suggests that mothers' behavior does not lead directly to compulsive behavior in children, but that it influences children's behavior through the process of shaping fundamental properties of emotion in children. While no association was found between compulsive-like behavior and the anxiety trait, which has been considered the core of compulsion, the findings suggest that the anger trait plays a principal role in the genesis of compulsive-like behavior. We suggest new possibilities in obsession-compulsion research.

\section{Keywords}

Compulsive-Like Behavior, Rearing Attitudes, Emotional Traits, Children

\footnotetext{
${ }^{*}$ Corresponding author.
}

How to cite this paper: Yamauchi, H., Ogura, M., Mori, Y., Ito, H., \& Honjo, S. (2016). The Effects of Maternal Rearing Attitudes and Depression on Compulsive-Like Behavior in Children: The Mediating Role of Children's Emotional Traits. Psychology, 7, 133-144. http://dx.doi.org/10.4236/psych.2016.72016 


\section{Introduction}

According to the World Health Organization, obsessive-compulsive disorder (OCD) is one of the most disruptive psychological disorders in terms of the difficulties it causes in daily life. Patients with OCD are forced to dedicate a large part of each day to their compulsive acts or obsessional ideas, resulting in greatly lowered quality of life (Bobes, Gonzalez, Bascaran, Arango, Saiz, \& Bousono, 2001; Fontenelle, Fontenelle, Borges, Prazeres, Range, Mendlowicz et al., 2010; Hauschildt \& Moritz, 2011). In addition, OCD is not only intractable, but is prone to becoming chronic (Wewetzer, Jans, Muller, Neudorfl, Bucherl, Remschmidt et al., 2001). A greater understanding of this disorder is urgently needed.

In recent years, progress in understanding OCD from a biological psychiatry perspective has accelerated (Camfield, Sarris, \& Berk, 2011) because of good reactivity to pharmaceutical agents (Ravizza, Barzega, Bellino, Bogetto, \& Maina, 1996; Pigott \& Seay, 1999), studies pointing to associations with brain structures, functional abnormalities elucidated by methodological advances in neural science (Kellner, Jolley, Holgate, Austin, Lydiard, Laraia et al., 1991; Gehring, Himle, \& Nisenson, 2000), and clarification of the genetic factors that contribute to OCD (Lin, 2007; Pauls, Alsobrook, Goodman, Rasmussen, \& Leckman, 1995).

However, recent studies have also revealed that the organic dysfunctions behind various mental disorders can be precipitated by psychosocial factors. For example, depression, with similar good pharmaceutical reactivity to OCD, has been demonstrated to arise from certain intracerebral reactions triggered by perceptions of psychological stress (Burke, Davis, Otte, \& Mohr, 2005; Kaufman \& Charney, 2001). Furthermore, there are many cases of OCD in which onset are attributed to psychosocial mechanisms; some case studies indicate the involvement of psychological factors. However, the psychosocial factors contributing to OCD have not yet been empirically verified.

\subsection{OCD in Childhood and Compulsive-Like Behavior}

To date, the onset of OCD has generally been regarded as occurring from childhood or adolescence onward, with onset in infancy assumed to be an exceptional occurrence (Eichstedt \& Arnold, 2001). However, a survey by Nestadt, Samuels, Riddle, Bienvenu, Liang, LaBuda et al. (2000) reports an onset rate of around $10 \%$ among children under age 5. Other studies have reported comparable results, indicating the presence of many cases of infantile-onset OCD (Zohar, 1999; do Rosario-Campos, Leckman, Mercadante, Shavitt, Prado, Sada et al., 2001).

In contrast, Adams (1973) points out the appearance of compulsive-like behavior during the course of normal child development. This phenomenon has been called compulsive-like behavior (Evans, Leckman, Carter, Reznick, Henshaw, King et al., 1997; Evans, Lewis, \& Iobst, 2004; Glenn, Cunningham, \& Nananidou, 2012) and is believed to be exhibited by 2 - 3-year-olds in efforts to overcome new encounters or anxiety-provoking events.

Pietrefesa and Evans (2007), examining the associations between OCD and compulsive-like behavior, have clarified that they are associated with similar emotional mechanisms and have a common neuropsychological basis. Additionally, given the presence of similarities in psychosocial factors such as rearing environment and parental attitudes between children displaying compulsive-like behavior and those who develop OCD, Evans et al. (1997) assert the validity of conceptualizing OCD and compulsive-like behavior observed in the course of normative development on a linear continuum, and not as separate entities existing on different planes (Pietrefesa \& Evans, 2007).

Our current study captures compulsive-like behavior and OCD on a continuum. Given this perspective, we delve into the nature of child compulsive-like behavior that is considered within the norm and clarify the factors contributing to such behavior. This approach may contribute to increased understanding of the mechanisms behind the onset of pathological OCD and expanded possibilities for treatment.

\subsection{Effects of Maternal Rearing Attitudes and Depression on Compulsive-Like Behavior in Children}

There have been few empirical studies on the factors contributing to compulsive-like behavior; previous findings have mostly been limited to descriptions of compulsive-like behavior and descriptions of the personal characteristics associated with it (Pietrefesa \& Evans, 2007).

This study focuses on the psychosocial factors behind the development of compulsive-like behavior, specifi- 
cally those concerning the mother as caregiver. The mother, usually the person who spends the largest amount of time with the child from birth, is considered to have an extensive influence on development, particularly during childhood. Maternal influence is a factor that has been investigated in many empirical studies (Brumariu \& Kerns, 2010). Moreover, Guidano and Llotti (1983) have applied the attachment theory to OCD, proposing that parental rearing attitudes contribute to the onset and maintenance of compulsive behavior and OCD. Although the number of empirical studies is limited, a number have investigated maternal influence, and the results indicate that parental rearing patterns affect certain symptoms of OCD (Alonso, Menchon, Mataix-Cols, Pifarre, Urretavizcaya, Crespo et al., 2004) and that parental rearing attitudes are associated with the chance of OCD onset as well as age of onset (Lennertz, Grabe, Ruhrmann, Rampacher, Vogeley, Schulze-Rauschenbach et al., 2010). However, these studies have not succeeded in clarifying the mechanisms by which parental factors affect children, because these studies have focused on OCD in adulthood and employed retrospective design.

\subsection{Factors Contributing to Compulsive-Like Behavior and the Mechanisms Involved}

Regarding the generation of compulsive-like behavior, Adams (1973) states that compulsive-like behavior is employed as a strategy for lowering anxiety in the strange situation. OCD, classified as an anxiety disorder, is also believed to arise from heightened anxiety accompanying compulsive ideas in response to exposure to aversive stimuli; this anxiety leads to the execution of compulsive acts intended to alleviate or neutralize the anxious feelings. Other studies, however, associate obsessions and compulsions with emotions other than anxiety. For example, some studies point to an association between compulsion and anger (Whiteside \& Abramowitz, 2005), while others have drawn an association between aggression and obsessional ideas or compulsive acts (Stein \& Hollander, 1993). These findings consistently implicate the existence of some sort of emotion, such as anxiety, prior to a compulsive act. However, it is currently unclear which emotion may play a primary role in the genesis of compulsive acts.

The existence of OCD patients without clear pathological anxiety, as well as studies on brain function and neurology suggesting that OCD may have a basis separate from anxiety disorders, has focused attention on the possibility of capturing OCD not as a disorder with anxiety at its core, but as an independently categorized illness conceptualized as an assemblage of the clinical symptoms of obsession-compulsion (Bartz \& Hollander, 2006; Storch, Abramowitz, \& Goodman, 2008). As such, not only is study needed to determine which emotions may be affecting OCD, but investigation is also required as to whether there is any association between obsession-compulsion and emotion at all. Thus, this study examined the effects of psychosocial factors on compulsive-like behavior in children, employing emotional traits (the ease of invoking emotions, including anxiety and anger) as the mediating variable. Emotional traits are defined as proneness to particular emotional reactions or as the lowness of the threshold for such responses; these traits are generally stable and consistent over time (Lazarus, 1994; Lazarus, 2006). The concept of emotional traits originated with studies on trait anxiety; therefore, much research on emotional traits is associated with anxiety. However, more recently, applications to other emotions such as anger and joy have emerged.

Considering the above, this study was designed to examine the effects of maternal rearing attitudes and depression on children's compulsive-like behavior, employing children's emotional traits as the mediating variable. A hypothetical model is shown in Figure 1.

\section{Methods}

\subsection{Participants}

Participants were recruited from one city in Japan. Participants were 116 mothers ( $\mathrm{M}$ age $=35.16, \mathrm{SD}=4.70)$ of children between ages of 3 and 5 years $(M=4.24, S D=0.94,62$ males and 52 females). This study received approval from the ethics committee of the Nagoya University Graduate School of Education and Human Development.

\subsection{Measures}

Child Routines Inventory. The Child Routines Inventory (CRI) is a 19-item questionnaire created by Evans et al. (1997) to evaluate the frequency and intensity of overall compulsive-like behaviors. It is scored on a 5-point scale ranging from 1 (not at all/never) to 5 (very much/always). The CRI consists of two factors: "just-right" and 


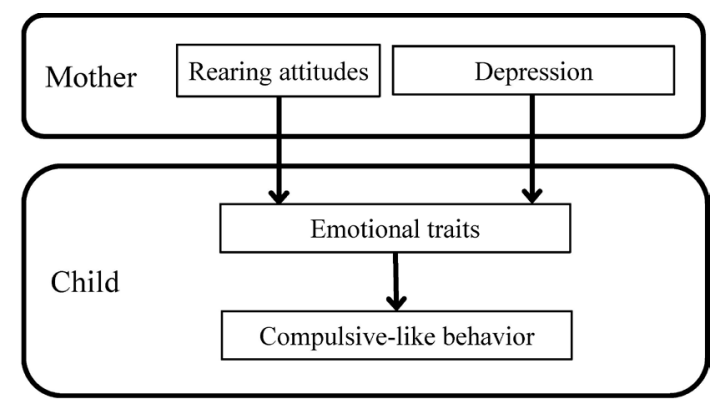

Figure 1. Hypothetical model.

"repetitive behaviors". Evans et al. reported that the internal consistency of the CRI is 0.92 .

The Japanese version of the CRI was developed with the authors' permission, subjected to back-translation, and then approved by the author. The Japanese version of the study employed a scale consisting of 19 items, with 2 subscales grouping just-right and repetitive behaviors. It calls for answers along a 5-point scale ranging from 1 (not at all/never) to 5 (very much/always), as in the original version.

Maternal Rearing Attitudes. The Parental Attitudes toward Child Rearing Scale (PACRS), which was developed by Sugawara, Yagishita, Takuma, Koizumi, Sechiyama, Sugawara et al. (2002), was employed in this study. To measure participants' current attitudes toward their children, Sugawara et al. altered the Parental Bonding Instrument (PBI) (Parker, Tupling, \& Brown, 1979) to create this scale, which consists of 25 items comprising 2 subscales (care and overprotection). Sugawara et al. conducted a questionnaire survey on 313 mothers in Japan and reported that the internal consistency of PACRS for mothers is 0.94 . The participants were asked to respond by recalling their attitudes toward the children up to the present on a 4-point scale ranging from 1 (does not apply) to 4 (applies).

Maternal Depression. To measure maternal depression, the Center for Epidemiologic Studies Depression Scale (CES-D) (Radloff, 1977) was used. Shima, Kano, Kitamura, \& Asai (1985) translated and confirmed the validity of the Japanese version of CES-D. The participants were instructed to respond by recalling their conditions over the past 6 months, including the present, on a 4-point scale from 0 (not even one day) to 3 (more than 5 days).

Child Emotional Traits Scale. An original scale on child emotional traits was developed from a free-response written preliminary survey conducted on mothers of young children aged 3 - 5 years. After extraction of items by the first author and two psychology doctorate students, content validity was checked by two professors of child psychology and psychiatry, one clinical psychologist, and one nursery school teacher who had 20 years of experience. The extracted items were compiled into a scale consisting of 44 items comprising 5 subscales (anger, joy, anxiety, humiliation, and guilt [items listed in Table 1]). The participants were instructed to respond by recalling their children's conditions over the past 6 months, including the present, on a 4-point scale ranging from 1 (never/seldom) to 4 (always/very often). The template is used to format your paper and style the text. All margins, column widths, line spaces, and text fonts are prescribed; please do not alter them. You may note peculiarities. For example, the head margin in this template measures proportionately more than is customary. This measurement and others are deliberate, using specifications that anticipate your paper as one part of the entire journals, and not as an independent document. Please do not revise any of the current designations.

\subsection{Procedure}

The questionnaire was distributed to mothers through kindergartens; all surveys were accompanied by an informed consent letter and a cover letter explaining the aim of our study. The forms were collected by mail.

\section{Results}

\subsection{Factor Analysis}

Child Routines Inventory. To confirm the factor structure of the Japanese version of the CRI, principal component analysis was conducted on the 19 items comprising the CRI. A one-factor solution was adopted based on a large decrement in the eigenvalue (6.92, 1.46, 1.36, etc.) after the first factor. While Evans et al. adopted two- 
Table 1. Principal component analysis results (promax rotation) of the Child Emotional Traits Scale.

\begin{tabular}{|c|c|c|c|}
\hline Item & $\mathbf{I}$ & II & III \\
\hline \multicolumn{4}{|l|}{ Factor $I<$ Anxiety $>$} \\
\hline Shy in front of others & 0.80 & -0.05 & -0.01 \\
\hline Bewildered in the presence of an unfamiliar child & 0.78 & -0.18 & 0.01 \\
\hline Dislikes being apart from parents or teachers when visiting a place for the first time & 0.78 & -0.08 & -0.06 \\
\hline Exhibits people-shyness in the presence of strangers & 0.72 & -0.20 & 0.03 \\
\hline Freezes when facing first-time experiences & 0.70 & -0.02 & 0.14 \\
\hline Looks anxious when parents or teachers show signs of moving elsewhere & 0.70 & 0.06 & 0.00 \\
\hline Bashful in front of unfamiliar adults or persons older than him/herself & 0.69 & -0.05 & 0.09 \\
\hline Finds new environments difficult (e.g., new kindergartens, playgroups) & 0.69 & -0.25 & 0.18 \\
\hline Fidgets when forced to express something in front of others & 0.67 & 0.03 & 0.06 \\
\hline Bashful when attention is paid to him/her by unfamiliar persons & 0.66 & 0.09 & 0.12 \\
\hline Frets and worries once he/she becomes aware of pending vaccinations or dentist appointments & 0.62 & 0.08 & -0.07 \\
\hline Is perfectly fine with being left alone in a room & -0.62 & -0.03 & 0.25 \\
\hline Will hold onto a parent's hand or not leave his/her side in dark places & 0.61 & 0.24 & -0.09 \\
\hline Becomes flustered when asked to do something he/she cannot do & 0.50 & 0.00 & 0.00 \\
\hline Is able to touch large animals or bugs he/she is seeing for the first time & -0.40 & 0.08 & 0.26 \\
\hline Seeing TV, books, or masks of ghosts or goblins worries the child that they might really appear & 0.39 & 0.30 & -0.13 \\
\hline Becomes angry when teased by siblings or other children & 0.37 & 0.27 & 0.06 \\
\hline Appears unaffected by having others watch when he/she messes up & -0.36 & -0.14 & 0.11 \\
\hline Appears humiliated upon soiling his/her pants & 0.33 & 0.14 & -0.23 \\
\hline Is bashful when praised by others & 0.32 & 0.30 & 0.09 \\
\hline \multicolumn{4}{|l|}{ Factor II $<$ Joy $>$} \\
\hline Is happy to see friends and relatives & -0.05 & 0.73 & 0.03 \\
\hline Is happy to be invited to play by friends & -0.13 & 0.73 & -0.08 \\
\hline Rejoices when given something he/she has wanted & -0.02 & 0.69 & 0.15 \\
\hline Rejoices when able to do something he/she could not do before & 0.02 & 0.66 & -0.11 \\
\hline Rejoices and breaks into a grin when praised by others & 0.02 & 0.64 & -0.09 \\
\hline Is happy when someone says "thank you" to him/her & 0.09 & 0.64 & -0.02 \\
\hline Is happy when parents or teachers play with him/her & 0.07 & 0.62 & 0.12 \\
\hline Is buoyant when there are plans for field trips and outings to which he/she is looking forward & -0.14 & 0.59 & -0.02 \\
\hline Is happy and thankful when someone helps him/her & 0.01 & 0.56 & -0.22 \\
\hline Becomes happy and content about little things & 0.17 & 0.52 & 0.18 \\
\hline \multicolumn{4}{|l|}{ Factor III < Anger > } \\
\hline Throws a fit when unable to get what he/she wants & -0.19 & 0.01 & 0.87 \\
\hline Becomes angry and difficult when interrupted in play & -0.12 & 0.07 & 0.79 \\
\hline Shouts when displeased with something & -0.15 & -0.14 & 0.72 \\
\hline Takes it out on objects when not allowed to do something he/she wanted to do & -0.02 & -0.04 & 0.63 \\
\hline Expresses dissatisfaction on his/her face when told to stop something he/she is doing & 0.07 & 0.34 & 0.52 \\
\hline Becomes angry when his/her belongings are damaged or broken by others & 0.08 & 0.23 & 0.46 \\
\hline Becomes angry when coaxed to eat something he/she dislikes & 0.13 & -0.23 & 0.45 \\
\hline Takes offense when reprimanded or cautioned about something & 0.21 & 0.08 & 0.39 \\
\hline Does not become discontent even when other children take his/her toys & 0.00 & 0.11 & -0.38 \\
\hline Contribution rate (\%) & 20.73 & 13.10 & 7.23 \\
\hline Cumulative contribution rate (\%) & 20.73 & 33.84 & 41.06 \\
\hline
\end{tabular}


factor solution for the original version of CRI, they also calculated the sums of scores for all items and named it "global CRI" as the variable that reflect overall obsessive-compulsive tendency. Cronbach's $\alpha$ was 0.90 , indicating sufficient internal consistency. Simple sums of scores for the 19 items were regarded as scores for children's compulsive-like behavior. High CRI scores indicate high frequencies/strengths of compulsive-like behavior.

Child Emotional Traits Scale. Principal component analysis (promax rotation) was performed on the 44 items composing the child emotional traits scale. A three-factor solution was adopted based on decrements in eigenvalues (8.42, 5.27, 2.85, 2.31, 1.86, etc.) and analysis of interpretability. Next, items with loadings of less than 0.30 for all principal components were removed. Repeating principal component analysis (promax rotation) without the removed items yielded a three-factor construct (Table 1). The first principal component was named "anxiety/shame", with heavy loading on items such as "bashful in front of others" and "looks anxious when parents or teachers show signs of moving elsewhere", connoting proneness to emotions such as shyness and anxiety. The second principal factor was named "joy", with heavy loading on items such as "is happy to see friends and relatives" and "is happy to be invited to play by friends", indicating readiness to feel joy. The third principal component was named "anger", with heavy loading on items like "throws a fit when unable to get what he/she wants" and "becomes angry and difficult when interrupted in play", denoting proneness to feelings of anger. High scores on each factor connote greater ease of feeling the emotion captured by the factor.

After converting the scores of reverse items, simple sums were calculated for the items showing heavy loading; these were used as subscale scores. All three subscales exhibited sufficient internal consistency.

Maternal Attitudes toward Child Rearing Scale. The 25 items composing the PACRS were also subject to principal component analysis (promax rotation). A three-factor solution was adopted based on decrements in eigenvalues $(4.91,3.00,2.06,1.61,1.49$, etc.). None of the principal components contained items with loadings under 0.30. Results are listed in Table 2. A two-factor construct consisting of care and overprotection had long been deemed appropriate for the original PBI. However, surveys using the PBI on large-scale samples have since demonstrated the validity of a three-factor construct consisting of care, overprotection, and encouragement of behavioral freedom (Gomezbeneyto, Pedros, Tomas, Aguilar, \& Leal, 1993; Murphy, Brewin, \& Silka, 1997). The three principal components extracted by our current analysis constituted the same constructs as those found in the previous studies mentioned above. The first principal component was care, consisting of such items as "I speak to my child in a warm and friendly voice"; the second principal component was encouragement of behavioral freedom, constructed from such items as "I let my child decide things for him/herself"; and the third principal component was overprotection, comprised of such items as "I am overprotective of my child".

\subsection{Descriptive Statistics}

Means, standard deviations, and values of Cronbach's $\alpha$ are given in Table 3. Mother's mean scores for depression $(\mathrm{M}=11.69, \mathrm{SD}=8.18)$ fell within the non-clinical range.

\subsection{Correlation Analysis}

The correlations between maternal rearing attitude scores, maternal depression scores, child emotional trait scores, and child compulsive-like behavior scores were calculated. Results are shown in Table 4. A number of significant correlations were noted between maternal rearing attitudes and child emotional traits, but no significant correlation was found between maternal depression and any of the emotional traits. The children's emotional traits for anxiety/shame and anger were found to be significantly correlated with compulsive-like behavior. However, no statistically significant correlation was seen between child compulsive-like behavior and any of the maternal attributes examined in this study.

\subsection{Path Analysis}

Path analysis using structural equation modeling was performed based on the hypothetical model shown in Figure 1. This path analysis led us to remove maternal depression from the model, because not only was there an absence of significant paths connecting it to emotional traits, but it was also lowering the goodness of fit of the entire model to the data. Similarly, no significant paths were found among care, anxiety/shame, and anger; between overprotection and joy; or between encouragement of behavioral freedom and anxiety/shame. The removal of these paths also increased goodness of fit, and the elimination of these yielded the final model. The 
Table 2. Principal component analysis results (promax rotation) of the Maternal Attitudes toward Child Rearing Scale.

\begin{tabular}{|c|c|c|c|}
\hline Item & I & II & III \\
\hline \multicolumn{4}{|l|}{ Factor $\mathbf{I}<$ Care $>$} \\
\hline I frequently smile at my child & 0.74 & 0.06 & 0.10 \\
\hline I am cold toward my child & -0.73 & 0.10 & 0.25 \\
\hline I am affectionate to my child & 0.70 & 0.12 & 0.02 \\
\hline I speak to my child in a warm and friendly voice & 0.67 & -0.08 & 0.01 \\
\hline I do not praise my child & -0.63 & 0.19 & -0.03 \\
\hline I understand the problems and worries my child is harboring & 0.62 & 0.00 & 0.22 \\
\hline I make my child feel unwanted & -0.60 & 0.07 & 0.05 \\
\hline I do not speak with my child very much & -0.56 & 0.01 & 0.13 \\
\hline I understand what my child needs or wants & -0.44 & 0.37 & -0.09 \\
\hline I am not helping my child as much as he/she needs & -0.38 & -0.25 & -0.02 \\
\hline I soothe my child when he/she is mentally unstable & 0.30 & 0.03 & 0.24 \\
\hline \multicolumn{4}{|l|}{ Factor II < Overprotection $>$} \\
\hline My child is incapable of looking after him/herself without me around & -0.04 & 0.77 & 0.01 \\
\hline I am overprotective of my child & 0.38 & 0.69 & 0.11 \\
\hline I am trying to make my child dependent on me & 0.03 & 0.69 & -0.05 \\
\hline I am invading my child's privacy & -0.22 & 0.58 & -0.02 \\
\hline I try to control everything my child does & -0.15 & 0.57 & 0.01 \\
\hline I often treat my child like a baby (younger than he/she really is) & 0.17 & 0.40 & -0.17 \\
\hline I am not happy with my child growing up & -0.19 & 0.31 & -0.05 \\
\hline \multicolumn{4}{|l|}{ Factor III < Encouragement of freedom $>$} \\
\hline I give my child as much freedom as possible & -0.18 & 0.04 & 0.74 \\
\hline I leave things up to my child & -0.41 & -0.09 & 0.69 \\
\hline I let my child do what he/she likes doing & 0.14 & 0.00 & 0.58 \\
\hline I think favorably of my child making his/her own decisions & 0.14 & 0.01 & 0.55 \\
\hline I enjoy talking about many things with my child & 0.40 & 0.02 & 0.50 \\
\hline I let my child dress as he/she wishes & -0.01 & -0.12 & 0.45 \\
\hline I let my child go out as often as he/she likes & 0.08 & -0.03 & 0.44 \\
\hline Contribution rate (\%) & 19.63 & 11.98 & 8.22 \\
\hline Cumulative contribution rate (\%) & 19.63 & 31.61 & 39.83 \\
\hline
\end{tabular}

Table 3. Descriptive statistics.

\begin{tabular}{|c|c|c|c|c|}
\hline & No. of items & M & $\mathrm{SD}$ & $\alpha$ \\
\hline \multicolumn{5}{|l|}{ <Mother > } \\
\hline \multicolumn{5}{|l|}{ Rearing attitudes } \\
\hline Care & 11 & 35.97 & 4.25 & 0.81 \\
\hline Overprotection & 7 & 13.08 & 3.19 & 0.68 \\
\hline Encouragement of freedom & 7 & 20.71 & 2.82 & 0.66 \\
\hline Depression & 20 & 11.69 & 8.18 & 0.85 \\
\hline \multicolumn{5}{|l|}{$<$ Child $>$} \\
\hline \multicolumn{5}{|l|}{ Emotional traits } \\
\hline Anxiety/shame & 19 & 47.25 & 10.89 & 0.90 \\
\hline Joy & 10 & 34.61 & 4.32 & 0.85 \\
\hline Anger & 9 & 21.25 & 4.80 & 0.76 \\
\hline Compulsive-like behavior & 19 & 45.87 & 13.05 & 0.90 \\
\hline
\end{tabular}


Table 4. Results of correlation analysis.

\begin{tabular}{|c|c|c|c|c|c|c|c|}
\hline & \multicolumn{4}{|c|}{ Mother } & \multicolumn{3}{|c|}{ Child } \\
\hline & Care & OP & EF & DEP & ANX & Joy & Anger \\
\hline \multicolumn{8}{|l|}{$<$ Mother $>$} \\
\hline \multicolumn{8}{|l|}{ Rearing attitudes } \\
\hline \multicolumn{8}{|l|}{ Care } \\
\hline Overprotection & -0.03 & & & & & & \\
\hline Encouragement of freedom & $0.23^{*}$ & $-0.20^{*}$ & & & & & \\
\hline Depression & $-0.35^{* *}$ & $0.24^{*}$ & -0.01 & & & & \\
\hline \multicolumn{8}{|l|}{$<$ Child $>$} \\
\hline \multicolumn{8}{|l|}{ Emotional traits } \\
\hline Anxiety/shame & 0.11 & $0.23^{*}$ & 0.07 & 0.02 & & & \\
\hline Joy & $0.21^{*}$ & -0.16 & $0.30^{*}$ & -0.08 & -0.04 & & \\
\hline Anger & 0.12 & 0.12 & $0.20^{*}$ & 0.03 & $0.34^{* *}$ & 0.08 & \\
\hline Compulsive-like behavior & 0.11 & 0.07 & 0.18 & 0.07 & $0.20^{*}$ & 0.15 & $0.51^{* *}$ \\
\hline
\end{tabular}

a) $\mathrm{OP}=$ Overprotection; $\mathrm{EF}=$ Encouragement of freedom; DEP = Depression; ANX $=$ Anxiety/shame. b) ${ }^{*} p<0.05 .{ }^{* *} p<0.01$.

resulting model is shown in Figure 2. The final model provided a good fit to the data $\left(\chi^{2}(14)=12.86, p=0.54\right.$, RMSEA $=0.00$, CFI $=1.00$ ).

Path analysis revealed five significant paths between maternal rearing attitudes and child emotional traits. Specifically, these paths ran from care to joy, from overprotection to anxiety/shame and anger, and from encouragement of behavioral freedom to joy and anger. A significant path was also determined to exist from child anger to compulsive-like behavior.

\section{Discussion}

The objective of this study was to examine the effects of maternal rearing attitude and maternal depression on compulsive-like behavior in children, using children's emotional traits as mediating variables. Path analysis using structural equation modeling of data collected from a questionnaire survey on mothers revealed that the PACRS's overprotection and encouragement to behavioral freedom subscales affected compulsive-like behavior in children via the children's emotional trait of anger. The findings were interpreted as follows.

Although no direct associations were found between maternal rearing attitudes or maternal depression and child compulsive-like behavior, path analysis using children's emotional traits as mediating variables revealed an indirect effect of maternal rearing attitude on children's compulsive-like behavior. This demonstrates a factor affecting child compulsive-like behavior that has not been examined empirically to date, and it clarifies that maternal factors affect compulsive-like behavior indirectly via the shaping of fundamental traits of child emotion. Previous studies on whether maternal factors affect child compulsive-like behavior and on the mechanisms whereby mothers exert their effects on its development have not yielded consistent results. Our study has been able to elucidate the maternal effects on the development of compulsive-like behavior by detailing the process leading to the occurrence of compulsive-like behaviors, using emotional traits as mediating variables. The next step in this research is to further examine these effects on a mechanistic level, continuing to configure emotional traits as mediating variables but including other factors pertaining to the caregiver and the familial environment in addition to maternal rearing attitudes.

While the emotional trait of anger was found to have an effect on compulsive-like behavior, no association was found between either anxiety/shame or joy and compulsive-like behavior. Pathological anxiety has hitherto been considered to be at the core of OCD. The reconsideration of OCD from perspectives other than that of anxiety has gained momentum in recent years, and findings from this study further support this reconsideration. 


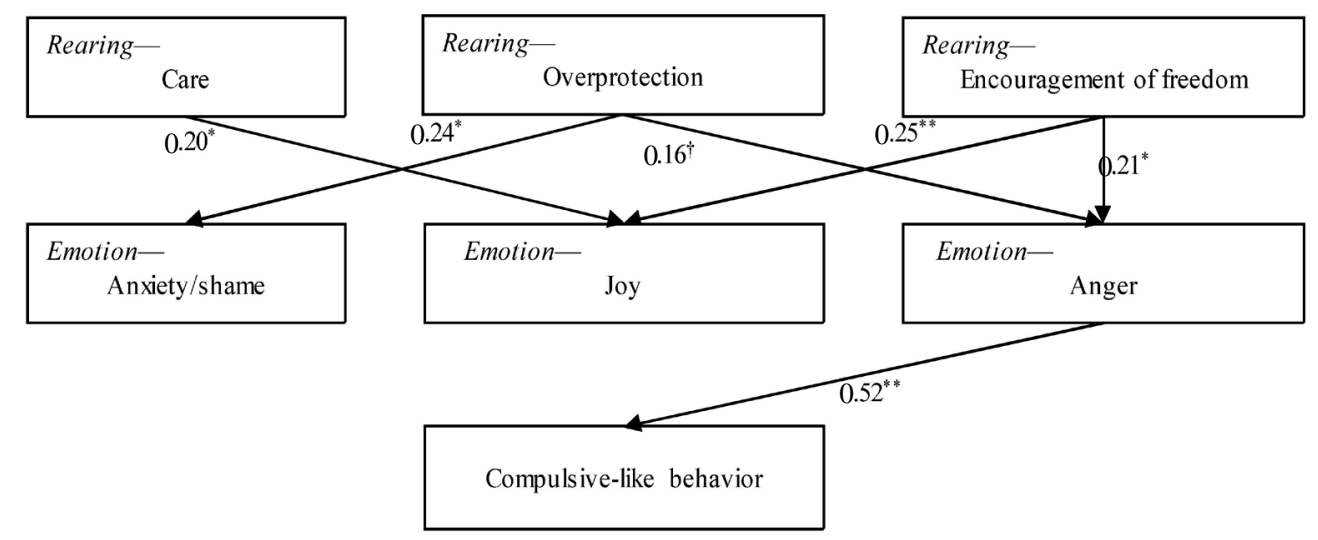

$\chi^{2}(14)=12.86, p=0.54, \mathrm{RMSEA}=0.00, \mathrm{CFI}=1.00$

${ }^{* * *} p<0.01,{ }^{*} p<0.05,{ }^{+} p<0.10$

Figure 2. Results of structural equation modeling.

Literature on the association between anger and compulsive-like behavior is rare. However, Freud (1913) pointed out the presence of deep emotions closely related to anger, such as hatred, as being at the core of compulsion; Freud's assertion was followed by similar interpretations by others through the years (Rubenstein, Altemus, Pigott, Hess, \& Murphy, 1995). Recent research documents an association between adult obsessivecompulsive tendencies and the expression of anger (Whiteside \& Abramowitz 2005; Whiteside \& Abramowitz, 2004). Our current findings conform to these studies and are believed to be a further demonstration of the association between compulsion and anger. The association between anger and compulsion has been largely overlooked to date, buried behind the general consensus of a close association between anxiety and compulsion. However, the findings from this examination, encompassing both anxiety and anger, yield the clarification that it is not anxiety associated with internalization issues but anger closely associated with externalization that has an effect on compulsive-like behavior. This is believed to constitute a new perspective from which to approach the fundamental nature of compulsion as a psychiatric issue. In the future, detailed analysis is needed on the association between anger and phenomena such as obsessive-compulsive personalities and OCD, which are beyond the scope of the compulsive-like behavior taken up in this study.

Five paths were extracted from the analysis of the effects of maternal rearing attitudes on children's emotional traits. Maternal overprotection was seen to elevate children's anxiety/shame. Over-interference from the mother has been previously shown to inhibit children's autonomy, creativity, and feelings of self-efficacy (Grolnick, Gurland, DeCourcey, \& Jacob, 2002), making children prone to feelings of anxiety or shame. Moreover, parental overprotection deprives children of opportunities to freely experience emotions and to deal with them on their own. This not only inhibits the development of control over negative emotions like anger or anxiety, but also leads to the accumulation of anger, as constant parental control is believed to lead to the intensification of anger.

Our findings also demonstrated that high scores in terms of maternal rearing attitudes surrounding care and encouragement of behavioral freedom elevate children's feelings of joy. The secure base concept of attachment theory holds that feelings of being protected by parents promote explorative behavior in children, contributing to richness of emotion. The formation of a secure attachment through affectionate care and the freedom to explore due to this attachment are both considered conducive to the promotion of joy. However, a path was also found to exist from encouragement of behavioral freedom to anger. While overprotection elevates anger by limiting children's actions, encouraging freedom may, by not limiting children's actions, contribute to the maintenance or fortification of children's feelings of omnipotence or self-centeredness, resulting in anger as a consequence of the smallest limitation or dissatisfaction.

Two issues can be raised for future study. First, this study examined the factors that affect compulsive-like behavior in children, clarifying the effects of some psychosocial factors. To date, few studies have focused on psychosocial factors in the genesis of compulsive-like behavior, and data on children is particularly scarce. In the future, we need to focus not only on compulsive-like behavior, but also on obsessional ideation in children. 
Furthermore, studies on clinical groups of patients diagnosed with OCD should contribute to further clarification of the mechanisms leading to symptoms of obsession-compulsion. Second, this study was based on data collected through a questionnaire survey directly rendered by the mothers of children. However, evaluations from third parties such as teachers and qualitative data obtained through direct observation are often crucial in order to increase the accuracy of the measurements beyond what is possible via questionnaires alone. As such, additional study on obsession-compulsion is warranted; we need to increase the diversity of data collected on this topic in the future.

\section{Summary}

Compulsive-like behavior is a phenomenon that appears during the course of normative development in children. However, some empirical studies have suggested that compulsive-like behavior has common emotional and neuropsychological bases with pathological OCD. Investigation of the mechanisms behind the genesis of compulsive-like behavior in children may contribute to increased understanding of OCD. Thus, the aim of this study was to investigate the effects of maternal rearing attitudes and depression on compulsive-like behavior in children and how these effects were mediated by children's emotional traits. The questionnaire was completed by mothers of children aged 3 - 6 years $(\mathrm{N}=116)$. The questionnaire consisted of four measures: 1) children's compulsive-like behavior; 2) children's emotional traits (subscales: anxiety/shame, joy, anger); 3) maternal rearing attitudes (care, overprotection, encouragement of freedom); and 4) maternal depressive tendencies. Correlation analysis did not reveal any significant correlations between maternal factors and compulsive-like behavior in children. In contrast, path analysis using structural equation modeling to test the hypothesis that children's emotional traits play roles in mediating variables indicated that maternal rearing attitudes, overprotection, and encouragement of freedom influenced compulsive-like behavior in children through the children's anger trait. Maternal depression had no significant effects on children's emotional traits and compulsive-like behavior. These findings suggest that maternal behaviors do not directly influence compulsive behaviors in children but that they affect children's behavior through the process that shapes more fundamental individual differences in emotion among children. Furthermore, the result that not the children's anxiety but their anger trait was found to have an effect on compulsive-like behavior is also notable. This result supports recent reconsideration of the hitherto-held concept that anxiety lies at the core of OCD. A detailed investigation of the relationship between anger and OCD (and its peripheral phenomena) is urgently needed. The effects of maternal rearing attitudes on children's emotional traits were also revealed by this study. Overall, our study provides evidence regarding the mechanisms behind the genesis of compulsive-like behavior in children. Children's compulsive-like behaviors are affected by maternal rearing attitudes not directly but through the mediating influence of children's anger trait.

\section{Acknowledgements}

Financial support for this study was provided by the Ministry of Health, Labour and Welfare, Japan.

\section{References}

Adams, P. L. (1973). Obsessive Children: A Sociopsychiatric Study. New York: Brunner/Mazel.

Alonso, P., Menchon, J. M., Mataix-Cols, D., Pifarre, J., Urretavizcaya, M., Crespo, J. M. et al. (2004). Perceived Parental Rearing Style in Obsessive-Compulsive Disorder: Relation to Symptom Dimensions. Psychiatry Research, 127, $267-278$. http://dx.doi.org/10.1016/j.psychres.2001.12.002

Bartz, J. A., \& Hollander, E. (2006). Is Obsessive-Compulsive Disorder an Anxiety Disorder? Progress in Neuro-Psychophar-Macology \& Biological Psychiatry, 30, 338-352. http://dx.doi.org/10.1016/j.pnpbp.2005.11.003

Bobes, J., Gonzalez, M. P., Bascaran, M. T., Arango, C., Saiz, P. A., \& Bousono, M. (2001). Quality of Life and Disability in Patients with Obsessive-Compulsive Disorder. Europian Psychiatry, 16, 239-245. http://dx.doi.org/10.1016/S0924-9338(01)00571-5

Brumariu, L. E., \& Kerns, K. A. (2010). Parent-Child Attachment and Internalizing Symptoms in Childhood and Adolescence: A Review of Empirical Findings and Future Directions. Development and Psychopathology, 22, 177-203. http://dx.doi.org/10.1017/S0954579409990344

Burke, H. M., Davis, M. C., Otte, C., \& Mohr, D. C. (2005). Depression and Cortisol Responses to Psychological Stress: A Meta-Analysis. Psychoneuroendocrinology, 30, 846-856. http://dx.doi.org/10.1016/j.psyneuen.2005.02.010 
Camfield, D. A., Sarris, J., \& Berk, M. (2011). Nutraceuticals in the Treatment of Obsessive Compulsive Disorder (OCD): A Review of Mechanistic and Clinical Evidence. Progress in Neuro-Psychopharmacology \& Biological Psychiatry, 35, 887895. http://dx.doi.org/10.1016/j.pnpbp.2011.02.011

do Rosario-Campos, M. C., Leckman, J. F., Mercadante, M. T., Shavitt, R. G., Prado, H. D., Sada, P. et al. (2001). Adults with Early-Onset Obsessive-Compulsive Disorder. American Journal of Psychiatry, 158, 1899-1903. http://dx.doi.org/10.1176/appi.ajp.158.11.1899

Eichstedt, J. A., \& Arnold, S. L. (2001). Childhood-Onset Obsessive-Compulsive Disorder: A Tic-Related Subtype of OCD? Clinical Psychology Review, 21, 137-157. http://dx.doi.org/10.1016/S0272-7358(99)00044-6

Evans, D. W., Leckman, J. F., Carter, A., Reznick, J. S., Henshaw, D., King, R. A. et al. (1997). Ritual, Habit, and Perfectionism: The Prevalence and Development of Compulsive-Like Behavior in Normal Young Children. Child Development, 68, 58-68. http://dx.doi.org/10.2307/1131925

Evans, D. W., Lewis, M. D., \& Iobst, E. (2004). The Role of the Orbitofrontal Cortex in Normally Developing Compulsive-Like Behaviors and Obsessive-Compulsive Disorder. Brain and Cognition, 55, 220-234. http://dx.doi.org/10.1016/S0278-2626(03)00274-4

Fontenelle, I. S., Fontenelle, L. F., Borges, M. C., Prazeres, A. M., Range, B. P., Mendlowicz, M. V. et al. (2010). Quality of Life and Symptom Dimensions of Patients with Obsessive-Compulsive Disorder. Psychiatry Research, 179, 198-203. http://dx.doi.org/10.1016/j.psychres.2009.04.005

Freud, S. (1913). The Interpretation of Dreams. New York: The Macmillan Company. http://dx.doi.org/10.1037/10561-000

Gehring, W. J., Himle, J., \& Nisenson, L. G. (2000). Action-Monitoring Dysfunction in Obsessive-Compulsive Disorder. Psychological Science, 11, 1-6. http://dx.doi.org/10.1111/1467-9280.00206

Glenn, S., Cunningham, C., \& Nananidou, A. (2012). A Cross-Sectional Comparison of Routinized and Compulsive-Like Behaviours in Typical Children Aged from 2 to 11 Years. European Journal of Developmental Psychology, 9, 614-630. http://dx.doi.org/10.1080/17405629.2011.639139

Gomezbeneyto, M., Pedros, A., Tomas, A., Aguilar, K., \& Leal, C. (1993). Psychometoric Properties of the Parental Bonding Instrument in a Spanish Sample. Social Psychiatry and Psychiatric Epidemiology, 28, 252-255.

Grolnick, W. S., Gurland, S. T., DeCourcey, W., \& Jacob, K. (2002). Antecedents and Consequences of Mothers’ Autonomy Support: An Experimental Investigation. Developmental Psychology, 38, 143-155. http://dx.doi.org/10.1037/0012-1649.38.1.143

Guidano, V. F., \& Llotti, G. (1983). Cognitive Processes and Emotional Disorders. New York: Guilford.

Hauschildt, M., \& Moritz, S. (2011). Obsessive-Compulsive Disorder: Psychosocial Consequences and Quality of Life. A Review. Nervenarzt, 82, 281-289. http://dx.doi.org/10.1007/s00115-010-2961-4

Kaufman, J., \& Charney, D. (2001). Effects of Early Stress on Brain Structure and Function: Implications for Understanding the Relationship between Child Maltreatment and Depression. Development and Psychopathology, 13, 451-471. http://dx.doi.org/10.1017/S0954579401003030

Kellner, C. H., Jolley, R. R., Holgate, R. C., Austin, L., Lydiard, R. B., Laraia, M. et al. (1991). Brain MRI in Obsessive-Compulsive Disorder. Psychiatry Research, 36, 45-49. http://dx.doi.org/10.1016/0165-1781(91)90116-7

Lazarus, R. S. (1994). Emotion and Adaptation. New York: Oxford.

Lazarus, R. S. (2006). Stress and Emotion. New York: Springer.

Lennertz, L., Grabe, H. J., Ruhrmann, S., Rampacher, F., Vogeley, A., Schulze-Rauschenbach, S. et al. (2010). Perceived Parental Rearing in Subjects with Obsessive-Compulsive Disorder and Their Siblings. Acta Psychiatrica Scandinavica, 121, 280-288. http://dx.doi.org/10.1111/j.1600-0447.2009.01469.x

Lin, P. Y. (2007). Meta-Analysis of the Association of Serotonin Transporter Gene Polymorphism with Obsessive-Compulsive Disorder. Progress in Neuro-Psychopharmacology \& Biological Psychiatry, 31, 683-689. http://dx.doi.org/10.1016/j.pnpbp.2006.12.024

Murphy, E., Brewin, C. R., \& Silka, L. (1997). The Assessment of Parenting Using the Parental Bonding Instrument: Two or Three Factors? Psychological Medicine, 27, 333-341. http://dx.doi.org/10.1017/S0033291796004606

Nestadt, G., Samuels, J., Riddle, M., Bienvenu, O. J., Liang, K. Y., LaBuda, M. et al. (2000). A Family Study of Obsessive-Compulsive Disorder. Archives of General Psychiatry, 57, 358-363. http://dx.doi.org/10.1001/archpsyc.57.4.358

Parker, G., Tupling, H., \& Brown, L. B. (1979). A Parental Bonding Instrument. British Journal of Medical Psychology, 52, 1-10. http://dx.doi.org/10.1111/j.2044-8341.1979.tb02487.x

Pauls, D. L., Alsobrook, J. P., Goodman, W., Rasmussen, S., \& Leckman, J. F. (1995). A Family Study of Obsessive-Compulsive Disorder. American Journal of Psychiatry, 152, 76-84. http://dx.doi.org/10.1176/ajp.152.1.76

Pietrefesa, A. S., \& Evans, D. W. (2007). Affective and Neuropsychological Correlates of Children’s Rituals and Compul- 
sive-Like Behaviors: Continuities and Discontinuities with Obsessive-Compulsive Disorder. Brain and Cognition, 65, 36-46. http://dx.doi.org/10.1016/j.bandc.2006.02.007

Pigott, T. A., \& Seay, S. M. (1999). A Review of the Efficacy of Selective Serotonin Reuptake Inhibitors in Obsessive-Compulsive Disorder. Journal of Clinical Psychiatry, 60, 101-106. http://dx.doi.org/10.4088/JCP.v60n0206

Radloff, L. (1977). The CES-D Scale: A Self-Report Depression Scale for Research in the General Population. Applied Psychological Measurement, 1, 385-401. http://dx.doi.org/10.1177/014662167700100306

Ravizza, L., Barzega, G., Bellino, S., Bogetto, F., \& Maina, G. (1996). Drug Treatment of Obsessive-Compulsive Disorder (OCD): Long-Term Trial with Clomipramine and Selective Serotonin Reuptake Inhibitors (SSRIs). Psychopharmacology Bulletin, 32, 167-173.

Rubenstein, C. S., Altemus, M., Pigott, T. A., Hess, A., \& Murphy, D. L. (1995). Symptom Overlap between OCD and Bulimia-Nervosa. Journal of Anxiety Disorders, 9, 1-9. http://dx.doi.org/10.1016/0887-6185(95)91551-R

Shima, S., Kano, T., Kitamura, T., \& Asai, M. (1985). New Self-Rating Scale for Depression. Clinical Psychiatry, 27, 717723.

Stein, D. J., \& Hollander, E. (1993). Impulsive Agression and Obsessive-Compulsive Disorder. Psychiatric Annals, 23, 389-395. http://dx.doi.org/10.3928/0048-5713-19930701-10

Storch, E. A., Abramowitz, J., \& Goodman, W. K. (2008). Where Does Obsessive-Compulsive Disorder Belong in DSM-V? Depression and Anxiety, 25, 336-347. http://dx.doi.org/10.1002/da.20488

Sugawara, M., Yagishita, A., Takuma, N., Koizumi, T., Sechiyama, H., Sugawara, K. et al. (2002). Marital Relations and Depression in School-Age Children: Links with Family Functioning and Parental Attitudes toward Child Rearing. Japanese Journal of Educational Psychology, 50, 129-140. http://dx.doi.org/10.5926/jjep1953.50.2_129

Wewetzer, C., Jans, T., Muller, B., Neudorfl, A., Bucherl, U., Remschmidt, H. et al. (2001). Long-Term Outcome and Prognosis of Obsessive-Compulsive Disorder with Onset in Childhood or Adolescence. European Child \& Adolescent Psychiatry, 10, 37-46. http://dx.doi.org/10.1007/s007870170045

Whiteside, S. P., \& Abramowitz, J. S. (2004). Obsessive-Compulsive Symptoms and the Expression of Anger. Cognitive Therapy and Research, 28, 259-268. http://dx.doi.org/10.1023/B:COTR.0000021544.64104.29

Whiteside, S. P., \& Abramowitz, J. S. (2005). The Expression of Anger and Its Relationship to Symptoms and Cognitions in Obsessive-Compulsive Disorder. Depression and Anxiety, 21, 106-111. http://dx.doi.org/10.1002/da.20066

Zohar, A. H. (1999). The Epidemiology of Obsessive-Compulsive Disorder in Children and Adolescents. Child and Adolescent Psychiatric Clinics of North America, 8, 445-460. 